\title{
DO DOCUMENTO FINAL DA CONAE AO PLANO NACIONAL DE EDUCAÇÃO: UMA ANÁLISE DA META 19
}

\author{
DEL DOCUMENTO FINAL DE LA CONAE AL PLAN NACIONAL DE \\ EDUCACIÓN: UN ANÁLISIS DE LA META 19FROM CONAE FINAL
}

\author{
DOCUMENT TO THE NATIONAL EDUCATION PLAN: AN ANALYSIS \\ OF GOAL 19
}

RESUMO: A gestão democrática da educação tem sido tema corrente nas discussões educacionais tanto no âmbito da academia quanto no âmbito dos sistemas de ensino, em grande medida, por ser esta uma arena de disputas de projetos antagônicos de educação e sociedade. Este artigo objetiva analisar os sentidos de gestão democrática oriundos das discussões da sociedade travadas nas Conferências de Educação e consolidados no documento final da CONAE de 2010 frente aos sentidos dados na meta 19 do Plano Nacional de Educação - Lei no 13.005/2014.

PALAVRAS-CHAVE: Gestão democrática. Plano Nacional de Educação. Política educacional.

RESUMEN: La gestión democrática de la educación ha sido tema corriente en las discusiones educativas tanto en el ámbito de la academia y en el ámbito de los sistemas de enseñanza, en gran medida, por ser ésta una arena de disputas de proyectos antagónicos de educación y sociedad. Este artículo objetiva analizar los sentidos de gestión democrática oriundos de las discusiones de la sociedad trabadas en las Conferencias de Educación y consolidados en el documento final de la CONAE de 2010 frente a los sentidos dados en la meta 19 del Plan Nacional de Educación - Ley $n^{o}$ $13.005 / 2014$.

PALABRAS CLAVE: Gestión democrática. Plan Nacional de Educación. Política educativa.

ABSTRACT: The democratic management of education has been a recurring theme in educational discussions both within academia and within educational systems, largely because this is an arena of disputes over opposing projects in education and society.

${ }^{1}$ Universidade do Estado do Rio de Janeiro (Uerj), Rio de Janeiro - RJ - Brasil. Professora Adjunta da Faculdade de Educação da UERJ e Professora Colaboradora do Programa de Pós-graduação em Educação Agrícola da UFRRJ.E-mail: lucilialinop@yahoo.com.br.

${ }^{2}$ Universidade Iguaçu (Unig), Nova Iguaçu - RJ - Brasil. Professora Assistente da Universidade Iguaçu, RJ e Doutoranda em Educação do Programa de Pós-Graduação em Educação da UFF, RJ. E-mail: morgan.uff@gmail.com. 
This article aims to analyze the meanings of democratic management derived from the discussions of society held in the Conferences of Education and consolidated in the CONAE final document of 2010 in the face of the meanings given in goal 19 of the National Education Plan - Law 13.005 / 2014.

KEYWORDS: Democratic management. National Education Plan. Educational policy.

\section{Introdução}

O Brasil atravessa, no momento atual, grave crise política-institucional marcada por ações que infligem graves retrocessos às políticas educacionais, no sentido da redução do direito à educação e ameaça ao cumprimento das metas do Plano Nacional de Educação, tendo em vista os cortes no financiamento para a Educação devido a EC/95/2016, que impõem o 'novo' Reajuste Fiscal que prevê o congelamento dos gastos públicos primários por 20 anos. Esta e outras medidas se inserem em um 'novo'(velho) projeto político de redução do Estado implementado pelas forças políticas que assumiram o governo da República após o impeachment de Dilma Rousseff e que desde então vem redesenhando a legislação educacional, anulando conquistas e suprimindo direitos sociais.

Consideramos a gestão democrática da educação uma conquista importante para a democratização da educação no país, e partindo do pressuposto que o campo educacional é alvo de disputas de projetos de sociedade e educação antagônicos, e que o Plano Nacional de Educação 2014-2024 se insere nesse contexto de disputas quando de sua discussão nas Conferências Nacionais de Educação (CONAE), e posteriormente no Congresso Nacional, este artigo objetiva analisar o documento final da CONAE 2010 buscando extrair os sentidos de gestão democrática contidos no texto e confrontá-los com os sentidos explícitos no texto legal aprovado em 2014.

Entretanto, antes de adentrar nessa discussão, achamos necessário traçar breve histórico sobre a inserção da gestão democrática na legislação do país, como princípio constitucional.

\section{Gestão democrática e participação popular: uma conquista}

O movimento de abertura política que impulsionou a queda da ditadura civilmilitar trouxe ao Brasil um clamor que exigiu o alargamento dos espaços democráticos e de participação da sociedade na gestão da coisa pública no geral e da educação, em

RPGE - Revista on line de Política e Gestão Educacional, Araraquara, v. 22, n. esp.1, p. 67-83, mar., 2018. 
especial. A intensa participação de amplos setores da sociedade civil organizada garantiu que o Congresso Nacional Constituinte elaborasse uma Constituição Federal que incorporasse uma concepção de cidadania mais alargada. Da mesma forma, entidades representativas dos segmentos da comunidade acadêmica e dos trabalhadores em geral, assim como do movimento de educadores, articuladas no Fórum Nacional em defesa da Escola Pública ${ }^{3}$, lutaram para que a Constituição federal assegurasse a amplas parcelas da população, historicamente excluídas, o direito subjetivo à educação entre outros direitos sociais.

A temática da participação da sociedade e da gestão democrática, uma das principais propostas do FNDEP, trouxe para a legislação a constituição dos conselhos de controle social, em âmbito municipal, estadual e federal, e no artigo $n^{\circ} 206$ da Constituição Federal de 1988, em seu inciso VI, a gestão democrática do ensino público se constitui enquanto princípio norteador da educação nacional. (BRASIL, 1988)

A temática da gestão democrática ganha relevância e maior destaque na Lei de Diretrizes e Bases da Educação Nacional (LDB), promulgada em 1996, que no Artigo $3^{\circ}$ inciso VIII, consolida a 'gestão democrática do ensino público, na forma desta Lei e da legislação dos sistemas de ensino', como princípio em que o ensino será ministrado (BRASIL, 1996). No Artigo 14, vemos alguns pré-requisitos para a efetivação da gestão democrática:

Art. 14. Os sistemas de ensino definirão as normas da gestão
democrática do ensino público na educação básica, de acordo com as
suas peculiaridades e conforme os seguintes princípios:
I - participação dos profissionais da educação na elaboração do projeto
pedagógico da escola;
II - participação das comunidades escolar e local em conselhos
escolares ou equivalentes.

Entretanto cabe registrar, ao analisarmos a letra da lei e considerando o disposto no art. 61 da LDB que define quais são os profissionais da educação, pode-se inferir que os membros da comunidade escolar que não são profissionais da educação os estudantes, suas famílias e os trabalhadores da escola não caracterizados como profissionais - assim como a comunidade local podem ser excluídos legalmente da construção do Projeto político pedagógico da Unidade Escolar (UE). Cabe ainda registrar que os conselhos escolares têm também função pedagógica, além das funções

${ }^{3}$ Criado em 1987, foi uma força política importante durante o processo de elaboração do capítulo sobre educação presente na Constituição Federal de 1988.

RPGE - Revista on line de Política e Gestão Educacional, Araraquara, v. 22, n. esp.1, p. 67-83, mar., 2018. 
consultiva, deliberativa, fiscal e mobilizadora. Os alunos, seus responsáveis e a comunidade do entorno da escola poderiam não ter direito à voz neste contexto, o que é comum em muitas redes de ensino.

O Plano Nacional de Educação (Lei 13.005/2014) vigente avança na compreensão de gestão democrática da educação e paralelamente traz retrocessos ao interligar o tema a questões de mérito e desempenho, evidenciando as contradições e as disputas no campo educacional. Cabe destacar que, desde a promulgação da Constituição de 1988, que determinava a elaboração de uma Lei de diretrizes e bases da educação nacional, assistimos a disputa de projetos educacionais antagônicos, que apresentam concepções distintas de educação: uma alinhada a setores progressistas que defendem uma educação pública dentro da concepção emancipatória e libertadora, que tem no FNDEP seu principal articulador, e outra concepção alinhada a correntes neoliberais, políticos conservadores, e defendida por segmentos do empresariado nacional e pelas instituições educacionais privadas. Essas duas concepções se opõem no Congresso Nacional quando da disputa de projetos distintos de LDB, sendo que aquele que foi denominado projeto da sociedade brasileira foi preterido por manobra parlamentar pelo substitutivo que é aprovado e torna-se a Lei 9394/1996. Da mesma forma, durante a tramitação do PNE, quando novamente dois projetos entram em disputa o PNE da sociedade brasileira ${ }^{4}$, sendo que a Lei 10.172/2001 constitui mais uma vez a derrota das concepções progressistas, que ansiavam pela ampliação do direito a educação.

Com o início do Governo Lula, em 2003, presenciamos uma mudança de concepção no Ministério da Educação, com impactos na política educacional, fruto da ampliação do espaço de atuação dos movimentos sociais, e progressivamente vai instituindo ações que valorizam a diversidade, a inclusão, a participação e a gestão democrática, e se constituem em avanços no que tange a democratização do acesso à educação. A elaboração do novo Plano Nacional de Educação começa a se estruturar de forma pública na CONAE - Conferência Nacional de Educação, realizada em 2010, e antecedida de etapas municipais, estaduais e distrital. Entretanto, cabe destacar que as disputas no campo educacional persistem, inclusive no interior do MEC, com concessões ao movimento Todos pela Educação, capitaneados por setores do

${ }^{4}$ Amplamente discutido em Congressos Nacionais de Educação (CONED), organizados pelo Fórum Nacional em Defesa da Escola Pública.

RPGE - Revista on line de Política e Gestão Educacional, Araraquara, v. 22, n. esp.1, p. 67-83, mar., 2018. 
empresariado, e que a configuração do Congresso Nacional não muito diferente daquela que rejeitou em 1996 e 2001 as propostas progressistas defendidas pelo FNDEP.

Assim, embora o PNE tenha sido, em tese, resultado de consulta pública direta através da primeira CONAE - Conferência Nacional de Educação, realizadas em 2010, o documento que deu origem ao Plano, o documento final da Conferência Nacional de Educação, possui pontos de divergência flagrante com a lei, o que evidencia que o campo educacional é um campo de disputas.

\section{O contexto nacional: um cenário de disputas}

Após o breve histórico apresentado, cabe agora desvelar alguns pressupostos ideológicos fundamentais para o entendimento do texto, que apontam para o cenário de disputas em torno das políticas educacionais. Tais pressupostos são caudatários de uma ideia de sociedade brasileira influenciada fortemente por orientações acordadas entre os países de economia dependente e agências multilaterais e cujos termos apontavam para o fomento do capitalismo e de uma forma específica de gerenciamento das estruturas do Estado.

Os tratados, consensos e orientações emanados dos organismos multilaterais afetaram a educação brasileira de forma intensa, mas também foram combatidos, em especial, no âmbito da crítica. Diversos autores (VIEIRA, 1995; FRIGOTTO; CIAVATTA, 2003; GENTILI; SILVA, 2015; KRAWCZYK; VIEIRA, 2008; dentre outros) elaboraram análises sobre a penetração de tal ideário na organização e gerenciamento da educação brasileira. Estas críticas baseiam as análises aqui propostas.

No Brasil, em meados dos anos de 1990 a ofensiva neoliberal se consolidou de forma mais intensa com a eleição e recondução de Fernando Henrique Cardoso (FHC) (1995-98 e 1999-2002). Já em seu primeiro ano de governo FHC criou o Ministério da Administração Federal e Reforma do Estado (MARE) sob o comando do economista Luiz Carlos Bresser Pereira. O MARE lançou o Plano Diretor da Reforma do Aparelho do Estado (1995) partindo do pressuposto de que a administração pública racionalburocrática serviu ao intento de separar o público e o privado, mas que, feito isto, era preciso proceder à "transição programada de um tipo de administração pública burocrática, rígida e ineficiente, voltada para si própria e para o controle interno, para uma administração pública gerencial, flexível e eficiente, voltada para o atendimento do cidadão.” (BRASIL, 1995, p. 13) 
A tese principal do documento repousa sobre a ideia de crise do Estado e da necessidade inadiável de uma reforma no aparelho estatal afirmando que este "já não consegue atender com eficiência a sobrecarga de demandas a ele dirigidas, sobretudo na área social" (BRASIL, 1995, p. 10).

O diagnóstico da crise educacional pautava-se na ideia de que a expansão do atendimento já estava alcançada, sendo necessário agora debruçar-se sobre a qualidade do serviço oferecido. Qualidade esta que o Estado, segundo tal perspectiva, não foi capaz de assegurar durante o processo de expansão. Assim sendo,

A natureza pública e o monopólio estatal da educação conduzem, segundo essa perspectiva, a uma inevitável ineficácia competitiva da escola. Existe uma crise de qualidade porque os sistemas educacionais latino-americanos não se configuraram como verdadeiros mercados escolares regulados por uma lógica interinstitucional, flexível e meritocrática. A escola está em crise porque nela não se institucionalizaram os critérios competitivos que garantem uma distribuição diferencial do serviço, que se fundamente no mérito e no esforço individual dos "usuários" do sistema. No seu âmbito, não foi estabelecido o necessário sistema de prêmios e castigos, que recompensa ou pune as ações e decisões individuais; em suma, um sistema em que os "melhores" triunfam e os "piores" fracassam. (GENTILI, 1998, p. 18)

Assim, somente pela via da inserção da educação na lógica de mercado seria possível levar qualidade às escolas. Porém, é importante destacar que o termo qualidade neste contexto assume uma semântica que vai ao encontro das propostas neoliberais.

A educação ganha centralidade no processo de desenvolvimento econômicosocial das nações pelo ideário de que sua suposta melhoria traria avanços na economia e produtividade, mas também pelo fato de que os governos precisariam diminuir os gastos sob sua responsabilidade, transferindo o seu oferecimento, mas conservando mecanismos de avaliação e controle envolvendo, neste último a participação popular como elemento de pressão.

No entanto, como nenhum processo político se dá sem as contradições e disputas a ele inerente, é preciso reconhecer que, no contexto analisado havia dois projetos antagônicos em sua essência que se enfrentavam no nível discursivo e simbólico. Tais projetos derivaram nacionalmente em políticas híbridas, ou seja, nem completamente neoliberais nem completamente democratizantes e participativas. (DAGNINO, 2004)

RPGE - Revista on line de Política e Gestão Educacional, Araraquara, v. 22, n. esp.1, p. 67-83, mar., 2018 
Neste sentido, em busca de um projeto que tivesse um "mínimo razoável de legitimidade e aceitação social" os setores ligados aos projetos neoliberais impõem "um linguajar que ideologicamente leve a uma forma fetichizada e reificada de visão da realidade, ocultando o verdadeiro sentido das reformas e mostrando-as como "vontade popular" (MONTAÑO, 2014, p. 23)

A Conferência Nacional de Educação se insere neste contexto de influência, tendo como princípio a participação popular na construção da política educacional do Brasil. Neste sentido, a análise do Documento Final da CONAE e da lei por ele originada, no que tange à gestão democrática da educação pública, merece um esforço de análise buscando elementos de distorção entre o primeiro texto (que representa a expressão popular) e o segundo texto (que representa a interpretação dada pelos parlamentares).

\section{A Conferência Nacional de Educação}

As Conferências de educação se iniciaram a partir do primeiro semestre do ano de 2009 com etapas municipais, regionais e estaduais cuja culminância foi a Conferência Nacional de Educação, realizada no período de 28 de março a $1^{\circ}$ de abril de 2010. O Ministério da Educação estima que, somando-se os participantes de todas as etapas, 3,5 milhões de pessoas tenham participado do processo. (MEC, 2010)

A dinâmica da CONAE partia da análise de um documento base elaborado e distribuído pelo MEC aos sistemas de ensino. Durante as conferências eram propostas e aprovadas pelos delegados as modificações necessárias sob a ótica daquele grupo. Os delegados eleitos em cada etapa levavam suas propostas aprovadas para outra conferência que abarcava delegados de mais localidades que a anterior e o mesmo processo era executado até a Conferência Nacional.

O documento-base que foi encaminhado para a Conferência Nacional de Educação (CONAE) foi construído de forma a incorporar as deliberações das conferências municipais, regionais e estaduais.

Foram inseridas pelas comissões estaduais e do Distrito Federal, no Sistema de Relatoria da Conae 5.300 deliberações em parágrafos, com proposta de emendas de novos parágrafos, acrescidos ao documento. As propostas foram sistematizadas, com base em critérios regimentais, pela Comissão Especial de Dinâmica e Sistematização (CEDS), em Documento-Base da etapa nacional, com 2057 emendas encaminhada

RPGE - Revista on line de Política e Gestão Educacional, Araraquara, v. 22, n. esp.1, p. 67-83, mar., 2018. 
para apreciação dos/as delegados/as nas plenárias de eixo. Das seis plenárias de eixo, realizadas em 30 e 31 de março de 2010, resultaram 694 emendas, aprovadas pelos delegados/as e encaminhadas para apreciação e para deliberação na plenária final. Na plenária final da Conferência Nacional de Educação (Conae), foram aprovadas 677 e o conteúdo resultante de todo esse processo de sistematização está registrado neste documento. (BRASIL, 2010. p. 08)

O número de contribuições e de participantes em todas as etapas demonstra o espaço de discussão e deliberação aberto nacionalmente. Foi gerado um documento posteriormente enviado ao legislativo contendo a consolidação das proposições aprovadas. Em última instância, o Documento Final da CONAE representou a consolidação das propostas da sociedade para a educação brasileira.

\section{O documento final da CONAE 2010 - uma análise dos sentidos de gestão democrática}

O Documento Final da CONAE 2010, em sua estrutura, está dividido em uma apresentação, seguida de introdução e de 6 Eixos temáticos, a saber: I - Papel do Estado na Garantia do Direito à Educação de Qualidade: Organização e Regulação da Educação Nacional; II - Qualidade da Educação, Gestão Democrática e Avaliação; III Democratização do Acesso, Permanência e Sucesso Escolar; IV - Formação e Valorização dos Trabalhadores em Educação; V - Financiamento da Educação e Controle Social; VI - Justiça Social, Educação e Trabalho: Inclusão, Diversidade e Igualdade.

Inserida a expressão gestão democrática como filtro de busca, foram encontradas 46 recorrências dentre as quais uma foi descartada por estar incluída no sumário do documento. As demais ocorrências encontram-se distribuídas da seguinte maneira:

Tabela 1: Número de ocorrências do Termo "gestão democrática" no texto do Documento Final da CONAE 2010

\begin{tabular}{|l|c|}
\hline \multicolumn{1}{|c|}{ Localização } & $\begin{array}{l}\text { Número de } \\
\text { ocorrências }\end{array}$ \\
\hline Apresentação & 00 \\
\hline Introdução & 04 \\
\hline $\begin{array}{l}\text { Eixo I - Papel do Estado na Garantia do Direito à Educação de Qualidade: } \\
\text { Organização e Regulação da Educação Nacional }\end{array}$ & 05 \\
\hline Eixo II - Qualidade da Educação, Gestão Democrática e Avaliação & 26 \\
\hline
\end{tabular}

RPGE - Revista on line de Política e Gestão Educacional, Araraquara, v. 22, n. esp.1, p. 67-83, mar., 2018. 


\begin{tabular}{|l|c|}
\hline Eixo III - Democratização do Acesso, Permanência e Sucesso Escolar; & 05 \\
\hline Eixo IV - Formação e Valorização dos Trabalhadores em Educação; & 02 \\
\hline Eixo V - Financiamento da Educação e Controle Social; & 01 \\
\hline Eixo VI - Justiça Social, Educação e Trabalho: Inclusão, Diversidade e Igualdade. & 02 \\
\hline Total & 45 \\
\hline
\end{tabular}

Fonte: Construído pelas autoras com base no Documento Final da Conae

Conforme demonstrado na Tabela 1, o tema é mencionado em praticamente todas as partes do documento, excluindo-se apenas a Apresentação. Tal informação nos possibilita inferir a importância dispendida à temática nas discussões que se deram nos espaços deliberativos.

Durante a introdução, o documento afirma que existem 5 grandes desafios que devem ser enfrentados em prol da melhoria da educação brasileira. Dentre eles, a garantia de que as discussões e consensos decorrentes da conferência redundem em políticas públicas que garantam a "a gestão democrática e o desenvolvimento social” (p. 13). Não está explícito no trecho, ou antes desta recorrência no documento, qual é o sentido do termo, porém ainda na mesma página, afirma que este ponto (junto com outros) é imprescindível para "para assegurar, com qualidade, a função social da educação e das instituições educativas" (IDEM, IBDEM). Por fim, o texto afirma que

O processo poderá possibilitar, ainda, o aprofundamento da discussão sobre a responsabilidade educacional, envolvendo questões amplas e articuladas como gestão, financiamento, avaliação, formação e valorização profissional, em detrimento de uma concepção meramente fiscalizadora e punitiva sobre os/as educadores/as. Ou seja, poderá contribuir para o delineamento de uma concepção político-pedagógica em que o processo educativo articule-se com a ampliação e melhoria do acesso e da permanência com qualidade social para todos/as, consolidando a gestão democrática como princípio basilar da educação nacional. (IDEM, p. 14, grifos nossos)

O trecho nos indica, quando analisado, que o consenso do conjunto de sujeitos individuais e coletivos que fizeram parte da construção deste documento aponta para uma gestão democrática que se afasta de uma perspectiva meritocrática.

A esse respeito, Schedler (1999) esclarece que uma das dimensões das políticas de accountability, nomeada de enforcement, inclui a imposição de sanções e sistema de premiações em decorrência de resultados obtidos. O atrelamento das políticas de accountability a um sistema de punição e premiação reflete, segundo o autor, uma nova 
perspectiva institucional na qual mecanismos de monitoramento impedem que maus resultados passem despercebidos pelos reguladores.

Embora no âmbito internacional (em especial na Inglaterra e nos Estados Unidos da América) tais práticas já estivessem bastante difundidas no ano em se deram as discussões acerca do PNE de 2014, percebe-se que, no âmbito das conferências, tal ideário foi combatido.

O Eixo I do documento em questão traz como temática o "Papel do Estado na Garantia do Direito à Educação de Qualidade: Organização e Regulação da Educação Nacional" (p. 19) no qual focaliza a urgência da constituição do Sistema Nacional de Educação cujo papel deve ser

[...] articulador, normatizador, coordenador e regulamentador do ensino público e privado e financiador dos sistemas de ensino públicos (federal, estadual/DF e municipal), garantindo finalidades, diretrizes e estratégias educacionais comuns, mas mantendo as especificidades próprias de cada um. Em tal sistema, os conselhos nacional, estaduais, do Distrito Federal e, municipais, com gestão democrática, são fundamentais para a supervisão e manutenção das finalidades, diretrizes e estratégias comuns. (p. 22)

Em análise do trecho transcrito, pode-se perceber um elemento importante. É colocado que os conselhos de educação, devem também possuir sua gestão democraticamente organizada. Tal ideal está num contexto de valorização dos Conselhos como parte do necessário controle social da educação, da supervisão e manutenção daquilo que os entes federados possuem em comum. $\mathrm{O}$ alcance da gestão democrática se expande do que fora disposto na LDB (participação dos profissionais da educação na construção dos PPPs e participação das comunidades local e escolar nos conselhos escolares ou equivalentes) e alcança outros órgãos dentro da estrutura de um Sistema a ser instituído. Neste contexto, podemos afirmar que há um alargamento da atuação da gestão democrática explícito no conteúdo do documento.

O documento critica a visão fragmentada da gestão educacional que tem sido característica da educação brasileira apontando para a consolidação do Sistema Nacional de Educação como garantidor de políticas públicas necessárias à gestão democrática não apenas das instituições escolares, mas também dos sistemas dos entes federados. O Sistema trata da gestão democrática ao afirmar que ele "deverá contar com a efetiva participação da sociedade civil e da sociedade política na garantia do direito à

RPGE - Revista on line de Política e Gestão Educacional, Araraquara, v. 22, n. esp.1, p. 67-83, mar., 2018. 
educação" (p. 36). Tal participação dar-se-ia também em um sistema de avaliação e monitoramento do PNE.

As diretrizes delineadas para o novo PNE, dentro da temática do primeiro eixo colocam a gestão democrática como fator de destaque, afirmando que esta será realizada

[...] por meio do estabelecimento de mecanismos que garantam a participação de professores/as, de estudantes, de pais, mães ou responsáveis, de funcionários/as bem como da comunidade local na discussão, na elaboração e na implementação de planos estaduais e municipais de educação, de planos institucionais e de projetos pedagógicos das unidades educacionais, assim como no exercício e na efetivação da autonomia das instituições de educação básica e superior. (p. 38)

Percebe-se no corpo do texto que a gestão democrática é observada a partir da ótica da participação como elemento praticamente único. Os espaços em que a participação deve ser propiciada são muitos e isto, nos parece, é apenas potencialmente positivo.

Dizemos potencialmente positivo tendo em vista que a participação não é sinônimo de democracia sem que haja elementos que possibilitem a gestão democrática entendida como processo de socialização de poder. Neste sentido, "não basta [...] ter presente a necessidade de participação da população na escola. E preciso verificar em que condições essa participação pode tomar-se realidade” (PARO, 1992, p. 256)

O Eixo II, Qualidade da educação, gestão democrática e avaliação, aborda três temas tratados de maneira interligada no documento. A ligação dos três aspectos mencionados é explicitado de maneira clara no primeiro parágrafo do Eixo através do qual pode-se perceber que embora refiram-se à elementos distintos a realização de um interdepende da execução do outro:

A educação com qualidade social e a democratização da gestão implicam a garantia do direito à educação para todos, por meio de políticas públicas, materializadas em programas e ações articuladas, com acompanhamento e avaliação da sociedade, tendo em vista a melhoria dos processos de organização e gestão dos sistemas e das instituições educativas. (p. 39)

O sentido de gestão democrática, até então colocado apenas como participação, é ampliado no decorrer do texto e se desvela para o leitor tendo como fundamentação a 
[...] constituição de um espaço público de direito, que deve promover condições de igualdade, liberdade, justiça e diálogo em todas as esferas, garanti[ndo] estrutura material e financeira para a oferta de educação de qualidade, contribui[ndo] para a superação do sistema educacional seletivo e excludente e, ao mesmo tempo, possibilita[ndo] a interrelação desse sistema com o modo de produção e distribuição de riquezas, com a organização da sociedade, com a organização política, com a definição de papéis do poder público, com as teorias de conhecimento, as ciências, as artes e as culturas (p. 42-43)

O trecho transcrito nos revela uma democracia que ultrapassa, em muito, uma percepção procedimentalista dos processos democráticos na educação abarcando questões de justiça social, de igualdade e de diálogo como elementos constituintes de tais processos. A democracia se coloca, portanto, como um processo cujo resultado deve promover justiça e igualdade, garantir o funcionamento das instituições e contribuir para a superação de desigualdades no sistema educativo.

Alguns aspectos são colocados como imprescindíveis à construção desta gestão democrática apontada no documento: a autonomia didático-científica, administrativa, pedagógica e de gestão financeira, a representatividade social e a formação da cidadania. Ainda é explicitada a intenção de que a gestão democrática estenda-se não apenas ao âmbito de instituições públicas, mas também as instituições privadas devem ter como princípio a democracia na gestão.

A ideia consiste na compreensão de que "a gestão democrática da educação não constitui um fim em si mesma, mas um importante instrumento do processo de superação do autoritarismo, do individualismo e das desigualdades socioeconômicas." (p. 43)

Observando o aspecto mais pragmático, o documento coloca a importância da composição de fóruns e conselhos que possam abrir espaços de interlocução entre o poder público e a sociedade civil na proposição e acompanhamento das políticas públicas para a área. Os Conselhos de Educação, inclusive, com caráter consultivo, normativo e fiscalizador das ações do Estado são destacados como elementos indispensáveis à construção da democracia nos processos educativos.

Quanto ao provimento do cargo de dirigente das instituições de ensino, o documento é enfático e não deixa dúvidas quanto ao seu posicionamento ao dar destaque à instituição de

[...] mecanismos democráticos - inclusive eleição direta de diretores/as e reitores/as, por exemplo -, para todas as instituições

RPGE - Revista on line de Política e Gestão Educacional, Araraquara, v. 22, n. esp.1, p. 67-83, mar., 2018. 
educativas (públicas e privadas) e para os sistemas de ensino; e, ainda, implantar formas colegiadas de gestão da escola, mediante lei específica. (p. 44)

A escolha direta é colocada como procedimento indispensável à constituição de um ethos democrático no seio das instituições de ensino públicas e privadas. É importante destacar que ainda que o dirigente seja democraticamente eleito, seu poder durante a gestão é socializado com toda a comunidade escolar e local através de decisões colegiadas tomadas a partir da constituição dos conselhos.

\section{A tramitação do PNE e o texto final}

$\mathrm{Da}$ arena de disputas que se deu durante a conferência, gerou-se um Projeto de Lei (PL) enviado à Câmara dos Deputados para discussão e votação. $\mathrm{O}$ texto enviado ao legislativo, no que tange à gestão democrática, contraria bastante os sentidos expostos e analisados neste artigo contidos no texto do Documento Final da CONAE. O PL trazia em seu texto a seguinte redação: "Meta 19: Garantir, mediante lei específica aprovada no âmbito dos Estados, do Distrito Federal e dos Municípios, a nomeação comissionada de diretores de escola vinculada a critérios técnicos de mérito e desempenho e à participação da comunidade escolar" (BRASIL, 2010, s/p)

É interessante notar a discrepância do sentido de gestão democrática vencedor das disputas travadas pela sociedade através das Conferências de educação e a proposta de lei enviada à casa legislativa. Ao passo que o primeiro texto apontava para uma gestão democrática baseada no alargamento dos processos democráticos e espaços de discussão, o PL aponta para questões de mérito e desempenho que são base para uma proposta de educação que vai frontalmente de encontro ao proposto no documento.

Ao isolar os termos mérito e desempenho no documento final da CONAE, encontramos a ausência do primeiro termo (mérito) e 14 ocorrências do segundo termo, dentre as quais nenhuma refere-se ao diretor escolar. Tal constatação demonstra que a distorção do documento proposto pela sociedade para subsidiar a lei fora totalmente desfigurado no que tange ao critérios e sentidos da gestão democrática.

Ao longo da primeira fase de tramitação na Câmara dos Deputados, a meta 19 sofreu 74 propostas de emendas e deu entrada no Senado Federal, a partir do PL 103/2012 com a seguinte redação: "Meta 19: assegurar condições, no prazo de 2 (dois) anos, para a efetivação da gestão democrática da educação, associada a critérios 
técnicos de mérito e desempenho e à consulta pública à comunidade escolar, no âmbito das escolas públicas, prevendo recursos e apoio técnico da União para tanto." (BRASIL 2012. s/p) Esta redação prevaleceu até o fim da tramitação sendo publicado como texto do atual Plano Nacional de Educação, Lei n ${ }^{\circ}$ 13005/2014.

Para além da desconsideração da maior parte das discussões da CONAE, o texto da meta na Lei ainda ignora a proposição de se estabelecer enquanto princípio a gestão democrática também para as instituições privadas permitindo práticas centralizadoras, a não participação de docentes e discentes nas decisões pedagógicas e/ou administrativas nestas instituições.

Tais fatos demonstram o embate entre a democracia direta, na qual os sujeitos adquiriram voz e voto na construção do Documento Final da CONAE e os interesses da classe política, representantes legais em nosso sistema de democracia representativa. Expõe, neste sentido, a divergência do que pensa a sociedade e do que é impresso nos textos legais pelos responsáveis pela redação das leis em nosso país.

\section{Considerações finais}

Esse trabalho buscou chamar a atenção sobre as disputas de concepção na elaboração, tramitação e posterior aprovação da legislação educacional, um processo complexo, que reflete que mesmo quando se tem um governo considerado progressista isso não garante a hegemonia nas concepções educacionais. Entender o ocorrido no processo de tramitação do PNE, nos ajuda a ampliar a compreensão sobre o atual cenário político que de forma acelerada se empenha em tornar sem efeito as políticas educacionais pregressas.

Entretanto, ao nos debruçarmos sobre o cenário de aprovação da LDB e do PNE 2001-2011, quando os projetos progressistas foram derrotados e a legislação aprovada não contemplou os anseios do movimento dos educadores, representado pelo FNDEP, o processo de elaboração e posterior aprovação do PNE 2014-20124 se constitui em um avanço significativo. Assim, apesar do texto final da lei 13.005/2014 não ter incorporado na íntegra o deliberado na CONAE 2010, o PNE é um documento que assegura uma série de conquistas e representa parte dos anseios da comunidade educacional. Nesse sentido, em relação ao PNE 2001 (Lei 10.172/2001), consideramos que PNE 2014 traz outros avanços importantes no que tange ao direito a educação e a valorização dos profissionais da educação.

RPGE - Revista on line de Política e Gestão Educacional, Araraquara, v. 22, n. esp.1, p. 67-83, mar., 2018. 
Cabe destacar, no entanto, os esforços empreendidos pelo MEC, nos últimos anos, em implementar programas de formação para gestores, técnicos e conselheiros visando a consolidação da gestão democrática nas redes públicas municipais e estaduais, que foi contemplado, ainda que parcialmente, na Meta 19. Em tempos de instabilidade democrática, quando o cumprimento do PNE está ameaçado devido ao congelamento dos gastos, que inviabiliza inclusive os programas de formação de gestores e técnicos, contemplados na estratégia 19.5, que se refere aos conselhos escolares e conselhos municipais de educação, entre outras ações, descontinuadas, paralisadas pela asfixia financeira, as entidades do campo educacional se manifestam em defesa do PNE aprovado e de seu cumprimento.

Os ataques impingidos ao Fórum Nacional de Educação ${ }^{5}$, instância responsável por monitorar o cumprimento do PNE, hoje descaracterizado e sem condições de cumprir suas funções legais, reflete o descompromisso do governo Temer (2016-2018) com o PNE. Presenciamos nos últimos meses a proliferação de medidas que retiram direitos da população e que se constituem em ameaças à democracia brasileira, e nesse cenário se evidencia o desmonte das instituições públicas pelos cortes no seu financiamento, assim como a reconfiguração da política educacional, no sentido de aligeirar e precarizar a formação dos aluno das classes populares. A conjuntura atual aponta para o desmonte do estado e da res publica, e nesse sentido, a defesa do PNE configura-se como um movimento de resistência da concepção de educação como direito de todos e dever do Estado, da escola pública, gratuita, laica, inclusiva e republicana e do princípio da gestão democrática.

\section{REFERÊNCIAS}

BRASIL. Constituição da República Federativa do Brasil de 1988. Presidência da República, Casa Civil, Subchefia para Assuntos Jurídicos. Disponível em: <http://www.planalto.gov.br/ccivil_03/constituicao/constitui\%C3\%A7ao.htm>. Acesso em: 7 set. 2017.

BRASIL. Lei n. 9.394/96, de 20 de dezembro de 1996. Estabelece as diretrizes e bases da educação nacional. Diário Oficial da União, Brasília, DF. Seção 1, p. 27.833, 23 dez. 1996.

${ }^{5}$ Para aprofundamento da temática consultar Mec e Entidades da Sociedade Civil: O Fórum Nacional de Educação. Editorial disponível em: <http://www.scielo.br/scielo.php?pid=S010173302017000200271\&script=sci_arttext>. 
BRASIL. Lei ${ }^{\circ} 10.172$, de 9 de janeiro de 2001. Aprova o Plano Nacional de Educação. Diário Oficial da União, Brasília, DF, 10 jan. 2001.

BRASIL. Plano Nacional da Educação: proposta do executivo ao Congresso Nacional. Brasília: Ministério da Educação e do Desporto. Instituto Nacional de Estudos e Pesquisas Educacionais - INEP, 1998. 129p.

BRASIL. Projeto de Lei, $\mathbf{n}^{\mathbf{0}}$ 8035, de 2010, do Poder Executivo, que "aprova o Plano Nacional de Educação para o decênio 2011-2020 e dá outras providências" (PL803510). MEC, 2010. Disponível em: <www.camara.gov.br/proposicoesWeb/fichadetramitacao? idProposicao=490116>. Acesso em: 7 set. 2017.

BRASIL. Conferência Nacional de Educação. Anais da Conferência Nacional de Educação (Conae) 2010: Construindo o Sistema Nacional Articulado de Educação - o Plano Nacional de Educação, diretrizes e estratégias de ação (2010, Brasília, DF). - V.1 Brasília: MEC, 2011a.

CUNHA, Luiz Antônio Constant Rodrigues. Educação, Estado e democracia no Brasil. 4 ${ }^{\mathrm{a}}$ ed. Cortez Editora, 2001.

DAGNINO, Evelina. Construção democrática, neoliberalismo e participação: os dilemas da confluência perversa. Política \& Sociedade, v. 3, n. 5, p. 139-164, 2004.

FRIGOTTO, Gaudêncio.; CIAVATTA, Maria. Educação básica no Brasil na década de 1990: subordinação ativa e consentida à lógica do mercado. Educação \& sociedade, v. 24, n. 82, 2003.

GENTILI, Pablo. A falsificação do consenso: simulacro e imposição na reforma educacional do neoliberalismo. Petrópolis: Vozes, 1998.

GENTILI, Pablo.; SILVA, Tomaz Tadeu. Neoliberalismo, qualidade total e educação. Petrópolis: Vozes, 2015.

KRAWCZYK, Nora Rut.; VIEIRA, Vera Lucia. A reforma educacional na América Latina nos anos 1990: uma perspectiva histórico-sociológica. São Paulo: Xamã. 2008

MONTAÑO, Carlos. O canto da sereia: crítica à ideologia e aos projetos do" Terceiro Setor". Cortez Editora, 2014.

PARO, Vitor Henrique. Gestão da Escola Pública: a Participação da Comunidade.

Revista Brasileira de Estudos pedagógicos. Brasília, v.73, n.174, p.255-290, maio/ago., 1992.

SCHEDLER, Andreas. Conceptualizing accountability. In: SCHEDLER, Andreas; DIAMOND, Larry.; PLATTNER, Marc F. Restraining the state: conflicts and agents of accountability. The self-restraining state: power and accountability in new democracies. Lynne Rienner Publishers, Inc. 1999.

VIEIRA, Sofia Lerche. Neoliberalismo, privatização e educação no Brasil: política educacional impasses e alternativas. São Paulo: Cortez, 1995.

RPGE - Revista on line de Política e Gestão Educacional, Araraquara, v. 22, n. esp.1, p. 67-83, mar., 2018. 


\section{Como referenciar este artigo}

LINO, Lucília Augusta.; MORGAN, Karine Vichiett. Do documento final da Conae ao Plano Nacional de Educação: uma análise da meta 19. Revista on line de Política e Gestão Educacional, Araraquara, v. 22, n. esp.1, p. 67-83, mar., 2018. E-ISSN:15199029.

Submetido em: 04/10/2017

Aprovado em: 15/12/2017 